AperTO - Archivio Istituzionale Open Access dell'Università di Torino

\title{
Abstract 1163: Microenvironment targets in KRAS-mutated metastatic colorectal cancer
}

\section{This is the author's manuscript}

Original Citation:

Availability:

This version is available http://hdl.handle.net/2318/1695385

since 2019-03-25T14:37:09Z

Published version:

DOI:10.1158/1538-7445.AM2014-1163

Terms of use:

Open Access

Anyone can freely access the full text of works made available as "Open Access". Works made available under a Creative Commons license can be used according to the terms and conditions of said license. Use of all other works requires consent of the right holder (author or publisher) if not exempted from copyright protection by the applicable law. 


\section{Cancer

\section{Abstract 1163: Microenvironment targets in KRAS- mutated metastatic colorectal cancer}

Serena Marchio, Alice Bartolini, Sabrina Cardaci, Marco Soster, Giorgio Corti, Simona Lamba, Federico Bussolino, Davide Cora', and Federica D. Nicolantonio

DOI: 10.1158/1538-7445.AM2014-1163 Published October 2014

Article

Info \& Metrics

Proceedings: AACR Annual Meeting 2014; April 5-9, 2014; San Diego, CA

\section{Abstract}

The introduction of biodrugs, e.g. the anti-EGFR antibodies, was initially seen as a promise to radically change the landscape for patients with metastatic colorectal cancer. However, although EGFR-targeted therapies, combined with chemotherapy, have prolonged survival expectancy to 24 months, cure remains anecdotal. Target therapies suffer of high costs, important side effects, and low response rates: it is now clear that this approach as it was originally conceived failed to meet the majority of its expectations. Importantly, because of novel prescription guidelines, patients with KRAS-mutated tumors are excluded from

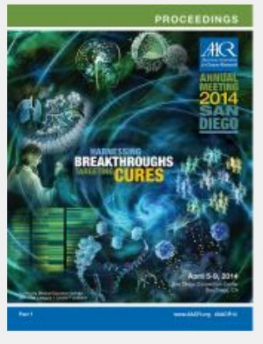

October 2014

Volume 74 , Issue 19

Supplement Table of

Contents

Index by Author

Search this issue

Sign up for alerts
(C) Permissions
(- Article Alerts
$\checkmark$ Email Article
C Citation Tools

Share

G+ 
We here propose an innovative strategy based on the identification of molecular targets specifically associated with the microenvironment of metastatic colorectal cancer in patients carrying oncogenic KRAS. For this purpose, we set up mice models of metastatic colorectal cancer by intrasplenic (to evaluate liver homing) and intrahepatic (to investigate liver colonization) implantation of human colorectal cancer cell lines (SW48 and LIM1215) in which oncogenic KRAS (G12D, G12V, G13D) variants have been somatically knockedin. We based our "target fishing" strategy on highthroughput, phage display-mediated proteomic screenings of deriving tumor samples ex vivo. Proteome signatures from the cognate cell lines in vitro served as a subtractive reference for the ex vivo biopanning, aimed at the identification of peptide ligands specific for non-epithelial components. By this combined biologicalgenetic-bioinformatics approach, we identified peptide/protein signatures selectively associated to metastasis microenvironments with controlled genetic backgrounds in vitro and in vivo.

We selected 2 target proteins and 2 targeting peptides, which were exploited for diagnostic and therapeutic purposes. First, we evaluated by IHC the presence and localization of the target proteins in samples (tumor, healthy liver) from a panel of human biopsies and from the described in vivo models. This analysis confirmed a specific enrichment in KRAS-mutated microenvironments. Second, we tested the capability of dye-conjugated targeting peptides to home to these same tumor microenvironments, observing a specific accumulation in target tissues, compared to their scrambled versions and to control tissues. Third, we investigated a potential anti-metastatic effect of these peptides when orthotopically co-injected with colorectal cancer cell lines; preliminary experiments revealed that 
the targeting peptides, but not the scrambled variants,

inhibit the onset of liver metastases from KRAS-mutated cell lines.

In summary, we obtained proof-of-concept results in preclinical studies and produced prototype compounds to provide innovative tools that can be translated into the clinical practice with a mid-term perspective.

Citation Format: Serena Marchio, Alice Bartolini, Sabrina Cardaci, Marco Soster, Giorgio Corti, Simona Lamba, Federico Bussolino, Davide Cora', Federica Di Nicolantonio. Microenvironment targets in KRASmutated metastatic colorectal cancer. [abstract]. In: Proceedings of the 105th Annual Meeting of the American Association for Cancer Research; 2014 Apr 5-9; San Diego, CA. Philadelphia (PA): AACR; Cancer Res 2014;74(19 Suppl):Abstract nr 1163. doi:10.1158/1538-7445.AM2014-1163

(C2014 American Association for Cancer Research.

$\Theta$ Previous

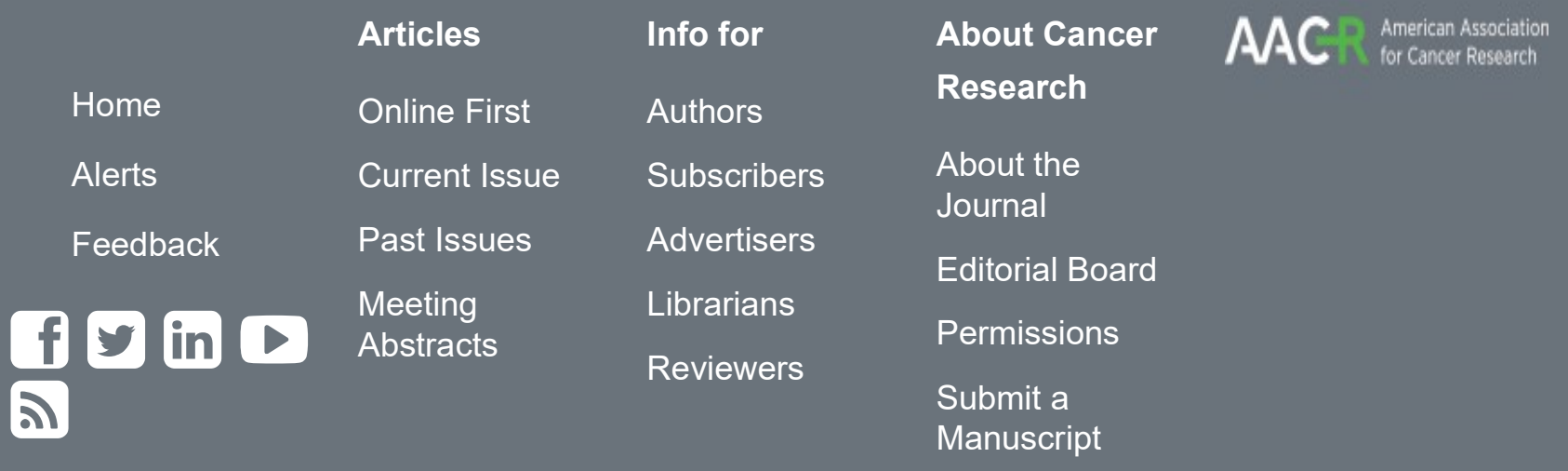


Advertisement 